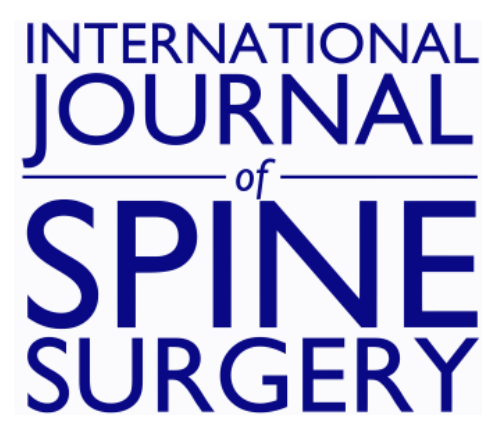

\title{
Indirect Decompression for the Treatment of Degenerative Lumbar Stenosis
}

\author{
Peter B. Derman, Donna D. Ohnmeiss, Abbey Lauderback and Richard D. Guyer
}

Int J Spine Surg 2021, 15 (6) 1066-1071

doi: https://doi.org/10.14444/8192

http://ijssurgery.com/content/15/6/1066

This information is current as of April 26, 2023.

Email Alerts Receive free email-alerts when new articles cite this article. Sign up at:

http://ijssurgery.com/alerts 


\title{
Indirect Decompression for the Treatment of Degenerative Lumbar Stenosis
}

\author{
PETER B. DERMAN, MD, MBA ${ }^{1}$; DONNA D. OHNMEISS, DRMED ${ }^{2}$; ABBEY LAUDERBACK ${ }^{1}$; AND \\ RICHARD D. GUYER, MD ${ }^{3}$ \\ ${ }^{I}$ Texas Back Institute, Plano, Texas, USA; ${ }^{2}$ Texas Back Institute Research Foundation, Plano, Texas, USA; ${ }^{3}$ Center for Disc Replacement at Texas Back Institute, Plano, \\ Texas, USA
}

\begin{abstract}
Background: Surgical treatment of symptomatic lumbar stenosis has traditionally included laminectomy for direct decompression. With increasing options for lumbar interbody fusion, there has been growing interest in indirect decompression to treat degenerative stenosis. The primary purpose of this study was to determine whether indirect decompression via anterior lumbar interbody fusion (ALIF) can provide symptomatic relief in patients with lumbar spinal stenosis. Secondary purposes were to (1) identify risk factors for failure of indirect decompression and (2) to identify risk factors for failure to obtain relief and to compare outcomes between patients undergoing stand-alone ALIF versusand those in whom ALIF was supplemented with posterior instrumentation.
\end{abstract}

Methods: Chart review was performed on a consecutive series of 568 patients undergoing single-level ALIF without posterior decompression to treat degenerative stenosis during a 5-year period. Failure of indirect decompression was defined as return to the operating room for direct decompression. Subgroup analysis was performed to compare patients who underwent stand-alone ALIF ( $n=247)$ vs those in whom supplemental posterior instrumentation was used (ALIF + PI; $n=321)$.

Results: Reoperation due to failure of indirect decompression occurred in 4.0\% (23/568) of patients. The only factor related to failure was age. Patients older than 60 years were more likely to fail indirect decompression than were younger patients $(7.0 \%$ vs $3.1 \%, P<0.05)$. ALIF and ALIF + PI subgroups both improved significantly when comparing preoperative to postoperative mean scores on Oswestry Disability Index (ODI), back pain, and leg pain (all $P<0.01$ ). There were no significant differences between these groups, including reoperation rate for direct decompression.

Conclusions: Indirect decompression via ALIF was effective in treating appropriately selected patients with degenerative lumbar spinal stenosis. Older patients are at higher risk for failure of indirect decompression-potentially because of greater osseous stenosis as well as subsidence due to age-related diminished bone density with subsequent loss of distraction.

Level of Evidence: 4.

Clinical Relevance: This study supports that indirect decompression via ALIF is a viable alternative to direct decompression in appropriately selected patients with degenerative stenosis.

Lumbar Spine

Keywords: indirect decompression, spinal stenosis, lumbar spine, anterior lumbar interbody fusion, clinical outcome, reoperation

\section{INTRODUCTION}

The surgical treatment of symptomatic lumbar stenosis refractory to nonoperative care has traditionally involved direct decompression in which the compressive pathology is excised via a posterior approach. In certain instances (eg, instability or deformity), fusion as well as decompression has been utilized. With increasing adoption of interbody techniques for lumbar fusion, there has been growing interest in indirect decompression for the treatment of symptomatic lumbar stenosis. Segmental distraction afforded by these interbody techniques is thought to increase foraminal height and reduce soft tissue infolding, thereby indirectly decompressing the neural elements. ${ }^{1}$ Interbody techniques can also contribute toward reduction of spondylolisthesis, another mechanism by which they may confer indirect decompression. ${ }^{2}$ In certain cases, such an approach may obviate the need for formal laminectomy, reducing potential surgical morbidity and operative time.

There is laboratory, radiographic, and clinical support for the concept of indirect decompression using interbody fusion. ${ }^{1-7} \mathrm{~A}$ cadaveric study determined that lateral lumbar interbody fusion (LLIF) significantly increased posterior disc height as well as canal and foraminal areas, ${ }^{6}$ and a recent study of 42 patients with severe degenerative lumbar stenosis reported an approximately 55\% increase in cross-sectional thecal sac area following LLIF. ${ }^{8}$ The clinical investigation of anterior lumbar interbody fusion (ALIF) has similarly 
demonstrated significantly increased foraminal height and posterior disc space height. In a series of patients with long-term follow-up, ALIF was associated with decreased ligamentum flavum area and increased thecal sac area due to ligamentotaxis in patients undergoing indirect decompression. ${ }^{4}$ In a study of 82 patients undergoing planned staged fusion of 1 to 3 levels for stenosis, formal decompression was avoided in $28 \%$ of patients as they experienced greater than $50 \%$ relief of their lower extremity symptoms after interbody fusion alone (ALIF or LLIF). ${ }^{9}$

The primary purpose of this study was to determine whether indirect decompression via ALIF can provide symptomatic relief in patients with lumbar spinal stenosis. Secondary purposes of the study were to identify risk factors for failure to obtain relief and to compare outcomes between patients undergoing stand-alone ALIF and those in whom ALIF was supplemented with posterior instrumentation.

\section{METHODS}

Based on a digital surgery record at a large multisurgeon spine practice, all cases of lumbar interbody fusion via an anterior approach performed between 2014 and 2018 were identified. Charts for these patients were retrospectively reviewed to determine study eligibility and to extract data. Patients were included if they underwent primary single-level ALIF with or without posterior instrumentation for symptomatic spinal stenosis in the absence of concomitant direct decompression. Previous laminectomy (but not attempted fusion) at the surgical level was permitted. Patients were excluded if they underwent surgery for the treatment isolated low back pain (without radiculopathy or neurogenic claudication), trauma, infection, or malignancy. All patients had exhausted nonoperative care prior to surgical intervention.

The decision whether to use posterior instrumentation was made at each surgeon's discretion for each patient. Posterior instrumentation was placed under fluoroscopic imaging in the majority of cases, with robotics or navigation used in fewer cases. If posterior instrumentation was used, the posterior procedure was performed during the same session as the ALIF, with a few patients undergoing a planned, staged posterior days after the ALIF. The decision whether to use posterior instrumentation was made preoperatively and was not based on the patient's initial response to ALIF.

Data recorded from the charts included general demographic information, symptom type (neurogenic claudication, radiculopathy, or both), Oswestry
Table 1. Overview of the study population.

\begin{tabular}{lcc}
\hline Characteristics and Variables & Mean & Range \\
\hline Age (years) & 50.1 & $19-81$ \\
& $\boldsymbol{N}$ & $\%$ \\
Gender & 301 & $53.0 \%$ \\
$\quad$ Female & 267 & $47.0 \%$ \\
Male & & \\
Symptoms & 508 & $89.4 \%$ \\
Radiculopathy & 13 & $2.3 \%$ \\
Neurogenic claudication & 47 & $8.3 \%$ \\
Both & & \\
Level operated & 1 & $0.2 \%$ \\
L2-3 & 5 & $0.9 \%$ \\
L3-4 & 143 & $25.2 \%$ \\
L4-5 & 419 & $73.8 \%$ \\
L5-S1 & & \\
Fusion technique & 247 & $43.5 \%$ \\
Stand-alone ALIF & 321 & $56.5 \%$ \\
ALIF + PI & \\
\hline
\end{tabular}

Abbreviations: ALIF, anterior lumbar interbody fusion; PI, posterior instrumentation.

Disability Index (ODI) scores, visual analog scale (VAS) data separately assessing back and leg pain, and reoperations. An overview of the study population is provided in Table 1. ODI and VAS scores from immediately before and at latest postoperative follow-up were utilized in the analysis. As described by Khalsa et al, response to ODI Section 7 (sleep question), was used to assess for the presence of preoperative rest pain. ${ }^{10}$ Reoperations, defined as a return to the operating room for a subsequent surgical procedure on the lumbar spine, were reviewed in detail. Failure of indirect decompression was defined as a reoperation including direct decompression at the index spinal level. Patients who had failed indirect decompression were compared to those who did not to determine whether any differences between the two groups could be identified. An additional subgroup analysis was performed to compare outcomes in patients who underwent stand-alone ALIF vs those who also received supplemental posterior instrumentation (ALIF + PI).

\section{Statistical Analysis}

Paired $t$ tests were used to compare preoperative to postoperative VAS and ODI scores. Mean values were compared between the patients who did and those who did not undergo subsequent direct decompressive surgery using independent $t$ tests, which were also used to compare values between the stand-alone ALIF and the ALIF + PI subgroups. Categorical data were compared between subgroups using chi-square analysis.

\section{RESULTS}

A total of 568 patients were identified who met the selection criteria. Reoperation due to failure of indirect 
Table 2. Comparison of patients for whom indirect decompression was successful vs those who underwent subsequent reoperation for direct decompression

\begin{tabular}{|c|c|c|c|}
\hline Variable & $\begin{array}{l}\text { Indirect Success } \\
\qquad(n=545)\end{array}$ & $\begin{array}{c}\text { Failed } \\
\text { Indirect } \\
(n=23)\end{array}$ & $P$ Value \\
\hline Mean age (years) & 49.8 & 56.6 & $<0.025$ \\
\hline Mean preop ODI & 43.8 & 46.5 & $>0.50$ \\
\hline $\begin{array}{l}\text { Mean preop VAS back } \\
\text { pain }\end{array}$ & 6.3 & 6.4 & $>0.50$ \\
\hline $\begin{array}{l}\text { Mean preop VAS leg } \\
\text { pain }\end{array}$ & $\begin{array}{c}4.9 \\
N(\%)\end{array}$ & $\begin{array}{c}5.6 \\
N(\%)\end{array}$ & $>0.30$ \\
\hline $\begin{array}{l}\text { Gender } \\
\text { Female } \\
\text { Male }\end{array}$ & $\begin{array}{l}288(95.7 \%) \\
257(96.3 \%)\end{array}$ & $\begin{array}{l}13(4.3 \%) \\
10(3.7 \%)\end{array}$ & $>0.05$ \\
\hline $\begin{array}{l}\text { Symptoms } \\
\text { Radiculopathy } \\
\text { Neurogenic } \\
\text { claudication } \\
\text { Both }\end{array}$ & $\begin{array}{c}13(100.0 \%) \\
43(91.4 \%)\end{array}$ & $\begin{array}{l}19(3.7 \%) \\
0(0.0 \%) \\
4(8.5 \%)\end{array}$ & $>0.05$ \\
\hline $\begin{array}{l}\text { Level operated } \\
\text { L2-3 } \\
\text { L3-4 } \\
\text { L4-5 } \\
\text { L5-S1 }\end{array}$ & $\begin{array}{c}1(100.0 \%) \\
5(100.0 \%) \\
139(97.2 \%) \\
400(95.6 \%)\end{array}$ & $\begin{array}{c}0(0.0 \%) \\
0(0.0 \%) \\
4(2.8 \%) \\
19(4.4 \%)\end{array}$ & $>0.05$ \\
\hline $\begin{array}{l}\text { ODI Section } 7^{\mathrm{a}} \\
\text { Score 0-2 } \\
\text { Score 3-5 }\end{array}$ & $\begin{array}{l}377(95.9 \%) \\
143(95.3 \%)\end{array}$ & $\begin{array}{c}16(4.1 \%) \\
7(4.7 \%)\end{array}$ & $>0.05$ \\
\hline $\begin{array}{l}\text { Fusion technique } \\
\text { Stand-alone ALIF } \\
\text { ALIF + PI }\end{array}$ & $\begin{array}{l}235(95.1 \%) \\
310(96.7 \%)\end{array}$ & $\begin{array}{l}12(4.9 \%) \\
11(3.4 \%)\end{array}$ & $>0.05$ \\
\hline
\end{tabular}

Abbreviations: ALIF, anterior lumbar interbody fusion; ODI, Oswestry Disability Index; PI, posterior instrumentation; VAS, visual analog scale.

${ }^{\mathrm{a}}$ Preoperative ODI Section 7 response not available for 2 patients.

decompression occurred in 23 patients (4\%). The timing of the direct decompression surgery ranged from 6 to 875 days with a mean of 187.6 days and a median of 96 days. Ten of the direct decompression procedures were performed within 90 days of the index surgery, with 5 additional cases performed between 90 and 120 days, and the remaining 8 such reoperations performed more than 120 days after the index surgery.

The patients who ultimately underwent direct decompression were compared to those who did not (Table 2). Older patients were significantly more likely to have failed indirect decompression $(P<0.01)$. Considering this difference, the relationship of age to failure of indirect decompression was explored further. Patients aged 60 years or older were more likely to have undergone subsequent direct decompression than patients who were younger than 60 years $(7.0 \%$ vs $3.1 \%, P<0.05)$. No other statistically significant differences were identified between the two cohorts when comparing gender, symptoms (radiculopathy vs neurogenic claudication vs both), preoperative ODI scores, ODI Section 7, preoperative VAS scores, level operated, and use of supplemental posterior instrumentation (all $P>0.05$ ).

\section{Return to the Operating Room}

The overall rate of return to the operating room for a lumbar spinal procedure was $14.1 \%$ ( 80 of 568 patients). As described earlier, 23 patients ultimately underwent a procedure that included a direct decompression at the index level. Other reasons for subsequent surgery were as follows: 25 removals of posterior instrumentation (22 for painful implants and 2 for suspected screw malposition); 11 operations to address degenerative changes at another lumbar segment ( 7 for adjacent segment degeneration and 4 at nonadjacent lumbar levels); 4 ALIF + $\mathrm{PI}$ in which the posterior procedure was postponed due to excessive bleeding during the anterior stage; 1 posterior instrumented fusion due to postoperative cage subsidence in a stand-alone ALIF; 1 instrumented posterior fusion in an ALIF patient following progression of a spondylolisthesis after a fall injury; 1 sacroiliac joint fusion; 2 superficial posterior wound infections; 6 revisions for pseudoarthrosis; and 6 spinal cord stimulator implantations.

\section{Stand-Alone ALIF vs ALIF + PI}

Patients were divided into 2 subgroups: stand-alone ALIF $(n=247)$ and ALIF + PI $(n=321)$. Both groups improved significantly when comparing the preoperative to postoperative mean scores for ODI, VAS back pain, and VAS leg pain (Table 3; all $P<0.01$ ). When comparing the 2 groups, there were no significant differences in these outcome evaluations preoperatively or postoperatively (all $P>0.50$ ). In the ALIF group, $4.9 \%$ of patients $(12 / 247)$ failed indirect decompression, which was not significantly different than $3.4 \%$ $(11 / 321)$ in the ALIF + PI group $(P>0.35)$. The overall reoperation rate was also not significantly different between groups (ALIF 12.1\% vs ALIF + PI 15.6\%, $P>0.20)$. Of note, in the ALIF + PI group, the most common reason for reoperation $(7.8 \%, 25 / 321)$ was for removal of posterior implants due to pain $(n=22)$ or suspected screw malposition $(n=3)$. In the stand-alone

Table 3. Preoperative and postoperative ODI and VAS scores for patients undergoing stand-alone ALIF vs ALIF With posterior instrumentation.

\begin{tabular}{lcccc}
\hline & \multicolumn{2}{c}{ Stand-Alone ALIF } & \multicolumn{2}{c}{ ALIF + PI } \\
\hline Outcome Measure & Preop & Postop & Preop & Postop \\
\hline ODI & 44.0 & 27.3 & 43.8 & 27.5 \\
VAS back pain & 6.3 & 2.8 & 6.2 & 3.0 \\
VAS leg pain & 5.0 & 1.9 & 5.0 & 2.1 \\
\hline
\end{tabular}

Abbreviations: ALIF, anterior lumbar interbody fusion; ODI, Oswestry Disability Index; PI, posterior instrumentation; VAS, visual analog scale.

Note: The mean scores in both groups improved significantly on all 3 measures (all $P$ $<0.01$ ) with no significant differences between the 2 groups on any of the measures preoperative or postoperative (all $P>0.50$ ). 
ALIF group, 8 patients $(3.2 \%)$ underwent reoperation for instability, subsidence, or pseudoarthrosis.

\section{DISCUSSION}

This study found that indirect decompression via ALIF was effective in treating lumbar spinal stenosis with statistically significant improvement in back pain, leg pain, and ODI scores. Only 4\% of patients later underwent direct decompression at the index level. This finding is consistent with the existing literature in which rates of subsequent direct decompression have been reported at $2 \%$ to $9.5 \% .^{11-13}$

In previous smaller studies, the following risk factors for failed indirect decompression have been identified: significant osteophytes (particularly those arising from the posterior end plates or significant enough to lock the facets), ossification of the posterior longitudinal ligament, preoperative motor deficit, rest pain, high scores on the Japanese Outcome Assessment questionnaire preoperatively, spondylolisthesis with greater than a moderate slip, and spondylolisthesis at L5-1 in an obese patient. ${ }^{10,11,13,14}$ Older age was the only factor investigated in the present study that was associated with failure of indirect decompression. While radiographic parameters were not directly assessed, this finding may be due to the additional spondylosis (and associated osseous stenosis) likely exhibited in older patients. It therefore follows that considering the size and location of osteophytes is reasonable in deciding whether direct decompression might be warranted as large osteophytes, unlike soft tissue, would not be expected to reduce with distraction and may tether the neural elements. Advanced age may also be a proxy for reduced bone density, and subsidence with loss of ligamentotaxis may also be implicated in the higher failure rate observed in older patients.

Contrary to the findings of Khalsa et al, ${ }^{10}$ this study did not identify an association between rest pain (as indicated by response to ODI Section 7) and rates of failure of indirect decompression. However, a number of differences exist that likely contribute to this discrepancy. Over $85 \%$ of patients in the Khalsa et al. study exhibited neurogenic claudication compared with just over $10 \%$ here. It may therefore be the case that rest pain is a better indicator for failure of indirect decompression for the treatment of central stenosis and associated neurogenic claudication than it is in the setting of radiculopathy. Furthermore, the definition of failure differed between studies with Khalsa et al considering postoperative pain scores and the present investigation utilizing return to the operating room.
While a variety of lumbar interbody fusion techniques are available, the current study focused specifically on patients undergoing ALIF rather than any other approaches. ALIF may offer advantages over other interbody techniques for performing indirect decompression. Some studies have found that ALIF is associated with significantly greater increases in foraminal height. ${ }^{15,16} \mathrm{By}$ providing a large exposure to the disc space, ALIF allows rapid disc tissue evacuation and end plate preparation, maximal implant size and surface area, and superior segmental and overall lumbar lordosis. ${ }^{17,18}$ There are also a wide variety of cage heights and angulations to facilitate achieving the desired degree of distraction and lordosis. However, ALIF is not always a viable option, depending on vertebral level and visceral anatomy.

This study included stand-alone ALIF as well as ALIF with supplemental posterior instrumentation. There were no significant differences in the clinical outcome, failure rates of indirect decompression, or reoperation rates when comparing the ALIF vs ALIF + PI groups. This supports the notion that posterior fixation may be omitted in appropriately indicated patients without causing undue risk of reoperation or poor outcomes. Foregoing posterior instrumentation reduces operative time and implant costs, preserves the posterior tissues, and eliminates the risk of pedicle screw breaches as well as the possible need for subsequent surgery to remove painful posterior instrumentation (which occurred in $10.1 \%$ of ALIF + PI patients in the current series). Further investigation is needed to determine which cases necessitate posterior instrumentation, but it may be prudent in patients with Grade II or greater spondylolisthesis, segmental instability, deformity, or poor bone stock.

This study is not without limitations. The decision of whether direct decompression was performed at the time of the index procedure was made by the treating surgeon without a standardized algorithm, and only patients in whom indirect decompression was relied upon were followed. The retrospective, nonrandomized design of the current study was not optimal. Details of the criteria used by surgeons to decide to employ only indirect decompression or to include posterior fixation could not be determined. However, the low rate of reoperation for direct decompression suggests that the surgeons selected appropriate cases for indirect decompression in the large majority of cases. What the results cannot address is whether more patients may have been appropriate candidates for indirect decompression but received direct decompression nonetheless. Furthermore, any patients who might have done poorly and undergone subsequent direct decompression at another practice would not have 
been captured. This would have artificially reduced the observed failure rate. Due to the focus on ALIF, nearly three-quarters of the patients in this study underwent surgery at the L5-S1 level, primarily for radiculopathy rather than neurogenic claudication. The results presented herein are therefore most applicable to patients with these clinical characteristics. Finally, radiographic and other imaging parameters were not collected or included in the analysis. Future studies investigating the impact of particular imaging findings would add to the understanding of this topic.

\section{CONCLUSION}

The results of this study suggest that indirect decompression via ALIF is effective in treating lumbar spinal stenosis with significant improvements in back pain, leg pain, and ODI scores. Only $4 \%$ of patients failed indirect decompression and subsequently underwent direct decompression at the index level. Older age (especially greater than 60) was the sole risk factor identified for failure of indirect decompression. These findings add to the developing understanding of the strengths and limitations of indirect decompression via lumbar interbody fusion and should aid surgeons in appropriately indicating and counseling their patients.

\section{REFERENCES}

1. Rao PJ, Maharaj MM, Phan K, et al. Indirect foraminal decompression after anterior lumbar interbody fusion: a prospective radiographic study using a new pedicle-to-pedicle technique. Spine J. 2015;15(5):817-824. doi:\%2010.1016/j.spinee.2014.12.019.

2. Ko M, Park SW, Kim YB. Correction of spondylolisthesis by lateral lumbar interbody fusion compared with transforaminal lumbar interbody fusion at L4-5. J Korean Neurosurg Soc. 2019;62(4):422-431. doi:10.3340/jkns.2018.0143.

3. Odeh K, Rosinski A, Nguyen J, et al. Anterior lumbar interbody fusion may provide superior decompression of the foraminal space compared with direct foraminotomy: biomechanical cadaveric study. World Neurosurg X. 2020;135:e71-e76. doi:10.1016/j. wneu.2019.10.139.

4. Ohtori S, Orita S, Yamauchi K, et al. Change of lumbar ligamentum flavum after indirect decompression using anterior lumbar interbody fusion. Asian Spine J. 2017;11(1):105-112. doi:10.4184/ asj.2017.11.1.105.

5. Chen D, Fay LA, Lok J, et al. Increasing neuroforaminal volume by anterior interbody distraction in degenerative lumbar spine. Spine. 1995;20(1):74-79. doi:10.1097/00007632199501000-00014.

6. Marulanda GA, Nayak A, Murtagh R, et al. A cadaveric radiographic analysis on the effect of extreme lateral interbody fusion cage placement with supplementary internal fixation on indirect spine decompression. J Spinal Disord Tech. 2014;27(5):263-270. doi:10.1097/BSD.0b013e31828f9da1.
7. Wang M, Dalal S, Bagaria VB, et al. Changes in the lumbar foramen following anterior interbody fusion with tapered or cylindrical cages. Spine J. 2007;7(5):563-569. doi:10.1016/j. spinee.2006.10.019.

8. Shimizu T, Fujibayashi S, Otsuki B, et al. Indirect decompression with lateral interbody fusion for severe degenerative lumbar spinal stenosis: minimum 1-year MRI follow-up. J Neurosurg Spine. 2020:1-8. doi:10.3171/2020.1.SPINE191412.

9. Park D, Mummaneni PV, Mehra R, et al. Predictors of the need for laminectomy after indirect decompression via initial anterior or lateral lumbar interbody fusion. J Neurosurg Spine. 2020:1-7. doi:10.3171/2019.11.SPINE19314.

10. Khalsa AS, Eghbali A, Eastlack RK, et al. Resting pain level as a preoperative predictor of success with indirect decompression for lumbar spinal stenosis: a pilot study. Global Spine J. 2019;9(2):150-154. doi:10.1177/2192568218765986.

11. Choi K-. C, Ahn Y, Kang B-. U, et al. Failed anterior lumbar interbody fusion due to incomplete foraminal decompression. Acta Neurochir. 2011;153(3):567-574. doi:10.1007/s00701-010-0876-2.

12. Malham GM, Parker RM, Goss B, et al. Clinical results and limitations of indirect decompression in spinal stenosis with laterally implanted interbody cages: results from a prospective cohort study. Eur Spine J. 2015;24 Suppl 3:339-345. doi:10.1007/s00586015-3807-3.

13. Oliveira L, Marchi L, Coutinho E, et al. A radiographic assessment of the ability of the extreme lateral interbody fusion procedure to indirectly decompress the neural elements. Spine. 2010;35(26 Suppl):S331-7. doi:10.1097/BRS.0b013e3182022db0.

14. Nakashima H, Kanemura T, Satake K, et al. Unplanned second-stage decompression for neurological deterioration caused by central canal stenosis after indirect lumbar decompression surgery. Asian Spine J. 2019;13(4):584-591. doi:10.31616/ asj.2018.0232.

15. Hsieh PC, Koski TR, O'Shaughnessy BA, et al. Anterior lumbar interbody fusion in comparison with transforaminal lumbar interbody fusion: implications for the restoration of foraminal height, local disc angle, lumbar lordosis, and sagittal balance. J Neurosurg Spine. 2007;7(4):379-386. doi:10.3171/SPI-07/10/379.

16. Ahlquist S, Park HY, Gatto J, et al. Does approach matter? A comparative radiographic analysis of spinopelvic parameters in single-level lumbar fusion. Spine J. 2018;18(11):1999-2008. doi:10.1016/j.spinee.2018.03.014.

17. Mobbs RJ, Phan K, Malham G, et al. Lumbar interbody fusion: techniques, indications and comparison of interbody fusion options including PLIF, TLIF, MI-TLIF, OLIF/ATP, LLIF and ALIF. J Spine Surg. 2015;1(1):2-18. doi:10.3978/j.issn.2414469X.2015.10.05.

18. Sembrano JN, Yson SC, Horazdovsky RD, et al. Radiographic comparison of lateral lumbar interbody fusion versus traditional fusion approaches: analysis of sagittal contour change. Int $J$ Spine Surg. 2015;9:16. doi:10.14444/2016.

Funding: The authors received no financial support for the research, authorship, and/or publication of this article.

Declaration of Conflicting Interests: The authors declared no potential conflicts of interest with respect to the research, authorship, and/or publication of this article. 
Corresponding Author: Peter B. Derman, This manuscript is generously published free of charge Texas Back Institute, 6020 W Parker Rd \#200, Plano, TX 75093, USA; pderman@texasback.com by ISASS, the International Society for the Advancement of Spine Surgery. Copyright (C) 2022 ISASS. To see more or order reprints or permissions, see http://

Published 21 December 2021 ijssurgery.com. 